\title{
The guarding posture of females in the subsocial bug Elasmucha dorsalis (Heteroptera: Acanthosomatidae)
}

\author{
SHIN-ICHI KUDO \\ Laboratory of Applied Zoology, Faculty of Agriculture, Hokkaido University, Sapporo, 060-8589, Japan and \\ *Department of Biology, Naruto University of Education, Naruto, Tokushima, 772-8502, Japan; e-mail: skudo@naruto-u.ac.jp
}

\begin{abstract}
Key words. Heteroptera, Acanthosomatidae, Elasmucha, parental care, guarding posture, predator-prey interactions
\end{abstract}
\begin{abstract}
The subsocial bug Elasmucha dorsalis lays egg masses on the underside of the leaves of female plants of Aruncus dioicus. Each bug straddles her eggs and shields her offspring with her body, until they moult to the 2 nd instar. Females that attended aggregations of 2 nd and later instar nymphs feeding on fruit of inflorescences often settled close to the basal part of or just below the aggregation, and faced towards the base of the inflorescence. The nymphal aggregations often seemed to be too large for females to guard effectively. The position and orientation of females attending 2 nd or later instar nymphs probably enabled them to detect predators walking towards the nymphs.
\end{abstract}

\section{INTRODUCTION}

The offspring of many subsocial insects are potentially vulnerable to predators and/or parasitoids, but are effectively protected against these enemies by their mother (or father in some species) (Tallamy \& Wood, 1986; Trumbo, 1996). In the subsocial Elasmucha bugs, a variety of natural enemies attack the immatures (e.g., Melber et al., 1980).

The defensive tactics of a parent, and their offspring's behaviour, will be selected for increased efficiency against the enemies of the offspring in the arms race between subsocial insects and their enemies. Thus, the effectiveness of parental defence may depend on the enemy species, each of which has different attack tactics. There are large differences in the effectiveness of parental defence of subsocial phytophagous insects against different enemies, predators and parasitoids (e.g., Eberhard, 1975). Such differences may be associated with the position and posture of the parent attending the offspring (Kudo, 1996; Kudo \& Ishibashi, 1996).

In this paper, the guarding position and posture of the mother of the subsocial bug Elasmucha dorsalis (Jakovlev), which possibly serves to guard against walking predators, but not parasitoids, is described.

\section{MATERIAL AND METHODS}

Field observations were conducted in a forest on the shores of Lake Shikotsu, Hokkaido, in northern Japan. Adults of Elasmucha dorsalis emerging from hibernation breed on the dioecious host plant Aruncus dioicus (Kudo et al., 1989; Kudo \& Kuhara, unpubl.). Females lay about 40 eggs in a cluster on the underside of leaves of the female plant, usually in early July. First instar nymphs are quite inactive and remain in tight aggregations on the leaf on which they hatched, but, the aggregations of second or later instar nymphs move to the inflorescences to feed on the developing fruit. $E$. dorsalis females stay with their eggs and nymphs until they reach the fifth instar (Kudo et al., 1989).

In 1991, E. dorsalis females were marked soon after oviposition and censused periodically. The brood condition, which was that of the majority of individuals in each brood, was categorized into one of 12 classes: with one of 6 categories for the de- velopmental stage, eggs to the fifth instar, and two for the feeding site, inflorescence or leaf. The position and orientation of females were recorded at the time when they first appeared with the brood of a particular developmental stage (thus, females were counted only once for each class). Females adopted one of three positions: (1) settled centrally (i. e., half way between the most basal and apical individuals in an aggregation of offspring or straddling the aggregation), (2) settled in a basal position (i. e., within one-fourth of the length of an aggregation of offspring from the base or just below the aggregation), (3) settled in an apical position (i. e., within one-fourth of the length of an aggregation of offspring from the apex or just apical to the aggregation). Whether females orientated towards the apex, the base or sides, was also recorded for females that settled on an inflorescence. Additional data were also obtained from the research conducted on the same population in 1989.

In 1990 and 1991, the size of aggregations (the distance between the most basal and apical individuals in an aggregation) on inflorescences was measured. The number of nymphs per aggregation was not determined, because counting disturbed the nymphs.

\section{RESULTS AND DISCUSSION}

Females invariably straddled their offspring from the egg to the second instar ( 76 out of 76 females with eggs, 42 out of 42 females with 1 st instar nymphs, and 9 out of 9 females with newly moulted 2 nd instar nymphs). The same was observed in this population in 1988 (Kudo et al., 1989).

When attending later instar broods on inflorescences, however, females changed their position (Table $1 ; \chi^{2}=114.7$, d.f. $=$ $6, \mathrm{P}<0.001$, cells of the developmental stage with small expected values were combined): they often settled close to the base of a nymphal aggregation or just below the aggregation. Most of these females faced towards the base of the inflorescence (Table 1).

Second or later instar nymphs were usually found on inflorescences. Two female-attended aggregations, in which the nymphs were moulting to the 3 rd instar, were found on the underside of leaves. One female straddled the nymphal aggregation and the other had settled on the underside of the petiole of

\footnotetext{
* Corresponding address.
} 
TABLE 1. The posture adopted by Elasmucha dorsalis females attending nymphs on inflorescences of Aruncus dioicus.

\begin{tabular}{|c|c|c|c|c|c|c|c|c|c|c|}
\hline \multirow{3}{*}{$\frac{\text { Position }^{2}}{\text { Facing }}$} & \multicolumn{9}{|c|}{ No. females observed ${ }^{1}$} & \multirow{3}{*}{ Total } \\
\hline & \multicolumn{3}{|c|}{ Base } & \multicolumn{3}{|c|}{ Center } & \multicolumn{3}{|c|}{ Apex } & \\
\hline & base & apex & sides & base & apex & sides & base & apex & sides & \\
\hline \multicolumn{11}{|c|}{ Nymphal instars ${ }^{3}$} \\
\hline 2 nd & 8 & 2 & 0 & 11 & 5 & 1 & 1 & 1 & 0 & 29 \\
\hline 3 rd & 9 & 1 & 0 & 4 & 2 & 1 & 1 & 2 & 0 & 20 \\
\hline 4 th & 9 & 1 & 1 & 2 & 1 & 0 & 2 & 3 & 0 & 19 \\
\hline 5 th & 5 & 0 & 0 & 0 & 1 & 0 & 1 & 1 & 0 & 8 \\
\hline
\end{tabular}

'Data was recorded for females with offspring of a particular instar at the time when they first appeared in the field.

${ }^{2}$ Center: Females settling centrally (i.e., half way between the most basal and apical individuals in an aggregation of offspring or straddling the aggregation); base: Females settling in a basal position (i.e., within one-fourth of the length of an aggregation of offspring from the base, or just below the aggregation); apex: Females settling in an apical position (i.e., within one-fourth of the length of an aggregation of offspring from the apex, or just apical to the aggregation).

${ }^{3}$ The instar of the majority of nymphs in an aggregation.

the leaf on which the nymphs were aggregated and faced the base.

Aggregations of nymphs often spread along the stems of inflorescences. The size (length) of an aggregation increased with the age of the nymphs (Fig. 1; Spearman's rank correlation, $\mathrm{rs}=$ $0.552, \mathrm{P}<0.001)$ and was usually much larger than the attendant female (body length, mean \pm SD: $6.68 \pm 0.23 \mathrm{~mm}, \mathrm{n}=50$ ).

Maternal care by Elasmucha bugs provides an effective defence against predators (Melber \& Schmidt, 1975b; Honbo \& Nakamura, 1985; Kudo \& Nakahira, 1993; Mappes et al., 1997). In this population of $E$. dorsalis, the offspring are also exposed to very high predation pressure from ants. Females guard their offspring against this threat (Kudo et al., 1989). The straddling and shielding posture of Elasmucha females attending compact aggregations of eggs and 1st instar nymphs is likely to be an effective defence. However, 2nd and later instar nymphs of $E$. dorsalis often form large and loose aggregations (Fig. 1), because of the interference and/or competition between the nymphs. Females can not effectively guard such large nymphal aggregations by straddling them (e.g., Mappes \& Kaitala, 1994).

The defensive behaviour of Elasmucha females is triggered by visual stimuli from objects moving in front of them, tactile stimuli, or alarm pheromones released by injured nymphs (Melber \& Schmidt, 1975a; Maschwitz \& Gutmann, 1979; Kudo, 1990). On inflorescences, attendant $E$. dorsalis females often settled close to the base of or just below nymphal aggregations,

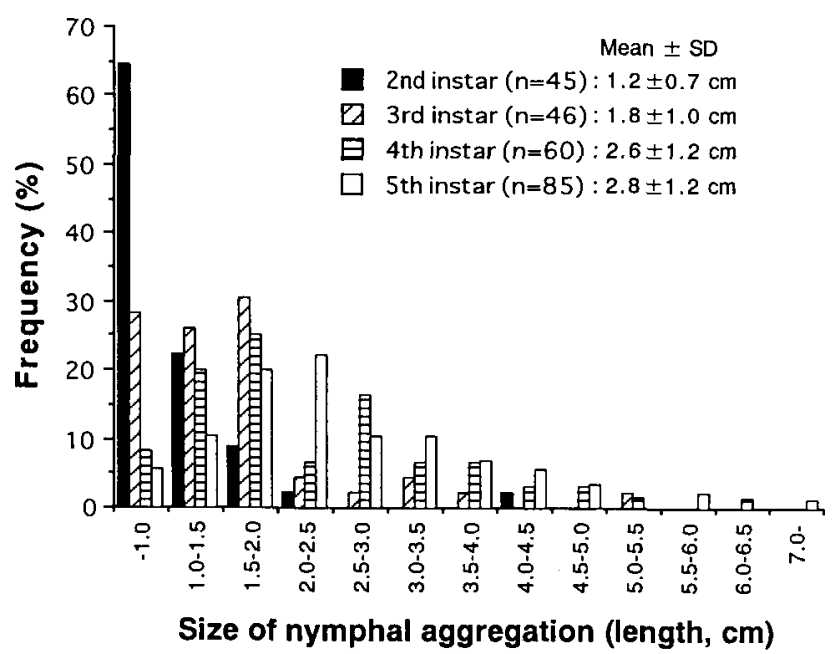

Fig. 1. Frequency distribution of the size of nymphal aggregations on inflorescences. Aggregation size: the distance between the most basal and apical individuals in an aggregation. and usually faced towards the base. This position and orientation is likely to be effective for intercepting predators walking towards the nymphs from the base of inflorescences, because the predators have to pass close to the female. This guarding posture (base-attending posture) is adopted by females of the related species, E. putoni (Kudo, 1996). Parent females of argid (Dias de Santos, 1975, 1976) or pergid (Macdonald \& Ohmart, 1993) sawflies and those of Gonioctena leaf beetles (Kudo et al., 1995) also show similar guarding tactics. These suggest remarkable behavioural convergence among phytophagous subsocial insects.

By contrast, the base-attending posture of females is unlikely to be effective against nymphal parasitoids, because the parasitoids can approach nymphs by flying and attack undetected from behind the attendant female (Kudo, 1996; Kudo \& Ishibashi, 1996). If the effect of parasitism on offspring mortality was higher than that of predation, parent females might evolve a guarding posture more effective against parasitoids. In a preliminary survey, an unidentified braconid nymphal parasitoid of $E$. dorsalis was found. However, the incidence of nymphal parasitism was very low in this population: only $1.2 \%$ of nymphs examined in $1990(\mathrm{n}=84)$ and $6.6 \%$ in $1991(\mathrm{n}=122)$. Thus, the guarding posture in $E$. dorsalis is likely to be maintained by the severe pressure from walking arthropod predators.

It is most likely that the straddling and shielding posture of females is more effective in protecting offspring against natural enemies than the base-attending posture when the offspring remain closely aggregated. This would account for why E. dorsalis females change their guarding posture according to the stage of development and degree of aggregation of their offspring. Similar shifts in parental guarding-posture are also reported for other subsocial insects, such as the acanthosomatid bug Elasmucha putoni (Kudo, 1996) and the argid sawfly Themos olfersii (Dias de Santos, 1975).

ACKNOWLEDGEMENTS. I thank N. Kuhara and N. Shida for their help in the field, and anonymous reviewers for their comments on the manuscript. This study was supported in part by a JSPS Fellowship for Japanese Junior Scientists, and by a Grantin-Aid (No. 09740581) for Scientific Research from the Ministry of Education, Science, Sports and Culture, Japan.

\section{REFERENCES}

Dias B.F. DE Santos 1975: Comportamento pre-social de sinfitas do Brasil Central. I. Themos olfersii (Klug) (Hymenoptera: Argidae). Stud. Entomol. 18: 401-432. 
Dias B.F. de Santos 1976: Comportamento pre-social de sinfitas do Brasil Central. II. Dielocerus diasi Smith, 1975 (Hymenoptera: Argidae). Stud. Entomol. 19: 461-501.

EberhaRd W.G. 1975: The ecology and behavior of a subsocial pentatomid bug and two scelionid wasps: strategy and counterstrategy in a host and its parasites. Smithson. Contr. Zool. 205: $1-39$.

Honbo Y. \& NaKamura K. 1985: Effectiveness of parental care in the bug Elasmucha putoni Scott (Hemiptera: Acanthosomatidae). Jpn. J. Appl. Entomol. Zool. 29: 223-229 (in Japanese, English abstr.).

Kudo S. 1990: Brooding behavior in Elasmucha putoni (Heteroptera: Acanthosomatidae), and a possible nymphal alarm substance triggering guarding responses. Appl. Entomol. Zool. 25: $431-437$.

Kudo S. 1996: Ineffective maternal care of a subsocial bug against a nymphal parasitoid: a possible consequence of specialization to predators. Ethology 102: 227-235.

Kudo S. \& Isuibssi II E. 1996: Maternal defence of a leaf beetle is not effective against parasitoids but is against pedestrian predators. Ethology 102: 560-567.

Kudo S. \& NAKAMIRA T. 1993: Brooding behavior in the bug Elasmucha signoreti (Heteroptera: Acanthosomatidae). Psyche 100: 121-126.

Kudo S., Sato M. \& Oliara M. 1989: Prolonged maternal care in Elasmucha dorsalis (Heteroptera, Acanthosomatidae). $J$. Ethol. 7: 75-81.

Kudo S., Ismbasin E. \& MAKINo S. 1995: Reproductive and subsocial behaviour in the ovoviviparous leaf beetle Gonioctena sibirica (Weise) (Coleoptera: Chrysomelidae). Ecol. Entomol. 20: $367-373$.
Macdonald J. \& OimarT C.P. 1993: Life history strategies of Australian pergid sawflies and their interactions with host plants. In Wagner M.R. \& Raffa K.F. (eds): Sawfly Life History Adaptations to Woody Plants. Academic Press, San Diego, pp. 485-502.

MAPpes J. \& KAitAla A. 1994: Experiments with Elasmucha grisea L. (Heteroptera: Acanthosomatidae): does a female parent bug lay as many eggs as she can defend? Behav. Ecol. 5: 314-317.

Mappes J., Mappes T. \& LAPPALAinen T. 1997: Unequal maternal investment in offspring quality in relation to predation risk. Evol. Ecol. 11: 237-243.

Maschwitz U. \& Gutmann C. 1979: Spur-und Alarmstoffe bei der gefleckten Brutwanze Elasmucha grisea. Insectes Soc. 26: 101-111.

Melber A. \& Scimidt G.H. 1975a: Sozialverhalten zweier Elasmucha-Arten (Heteroptera: Insecta). Z. Tierpsychol. 39: 403-414.

MeLber A. \& SCHMidT G.H. 1975b: Ökologische Bedeutung des Sozialverhaltens zweier Elasmucha-Arten (Heteroptera: Insekta). Oecologia 18: 121-128.

Melber A., Hölsciler L. \& Schmidt G.H. 1980: Further studies on the social behaviour and its ecological significance in Elasmucha grisea L. (Hem.-Het.: Acanthosomatidae). Zool. Anz. (Jena) 205: 27-38.

TAllamy D.W. \& WoOD T.K. 1986: Convergence patterns in subsocial insects. Annu. Rev. Entomol. 31: 369-390.

Trumbo S.T. 1996: Parental care in invertebrates. Adv. Stud. Behav. 25: 3-51.

Received May 31, 1999; accepted September 23, 1999 